\title{
Design impact on airflow patterns in fluidization units
}

\author{
Carlos Alberto Renaudo ${ }^{1 *}$, Diego Esteban Bertin ${ }^{1}$, Verónica Bucalá ${ }^{1}$ \\ ${ }^{1}$ Universidad Nacional del Sur, Department of Chemical Engineering, Planta Piloto de Ingeniería Química \\ (PLAPIQUI) - UNS-CONICET, Camino La Carrindanga Km. 7, (8000), Bahía Blanca, Argentina \\ *Correspondence: Carlos Alberto Renaudo (E-mail: carenaudo@plapiqui.edu.ar), Universidad Nacional del Sur, \\ Department of Chemical Engineering, Planta Piloto de Ingeniería Química (PLAPIQUI) - UNS-CONICET, Camino \\ La Carrindanga Km. 7, (8000), Bahía Blanca, Argentina
}

\section{Abstract}

The airflow behavior in a fluidization unit was integrally studied by means of experimental work and CFD simulation. The computational domain included the gas inlet pipe, plenum, perforated plate, fluidization chamber and the air outlet pipe. Different scenarios were simulated to allow distinguishing the best way to represent perforated plates distributors and elucidate the impact of the grid design on the fluidization performance. The simulated pressure drop across the distributor and the plenum flow pattern were in concordance with the experimental data. It was found that the distance between the peripheral holes and walls has a great impact on the airflow downstream the distributor.

Keywords: Fluidization; Computational Fluid Dynamics; Perforated Plate; Conical fluidized bed; Design

\section{Introduction}

Fluidized beds are very good mixers used for rapid mass and heat transfer operations, such as drying, coating and aggregation, either within the same piece of equipment or separately $[1,2]$. For this reason, they are used for a wide range of process engineering applications. Besides the bed, other components of the fluidization system have to be carefully specified. In fact, the plenum and airflow distributor design is key aspect to ensure a uniform airflow across the entire bed cross section, minimize the passage of solids to the plenum, reduce particles attrition and support the bed weight during the unit start up and shut down, etc. [3]. The distributor and the plenum design impact the system pressure drop and therefore the blower performance. Moreover, the grid dampens the pressure fluctuations derived from the blower [4]. In addition, the freeboard above a fluidization chamber must be high enough to allow the particles to disengage before the gas leaves the equipment $[5,6]$. The freeboard offers opportunities for additional contact between the dispersed and continuous phases, which can be important for many processes $[7,8]$.

The importance of the distribution plate on the fluidization behavior has been recognized in different areas, such as those of food [9], pharmaceutical [10] and combustion processing [11]. The pressure drop across the gas distributor is critical $[12,13]$. In fact, it must be high enough to dampen the gas fluctuations coming from the plenum and homogenize the flow entering the bed [14]. On the other

Received: October 24, 2018; revised: April 14, 2019; accepted: July 26, 2019

This article has been accepted for publication and undergone full peer review but has not been through the copyediting, typesetting, pagination and proofreading process, which may lead to differences between this version and the final Version of Record (VOR). This work is currently citable by using the Digital Object Identifier (DOI) given below. The final VoR will be published online in Early View as soon as possible and may be different to this Accepted Article as a result of editing. Readers should obtain the final VoR from the journal website shown below when it is published to ensure accuracy of information. The authors are responsible for the content of this Accepted Article.

To be cited as: Chem. Eng. Technol. 10.1002/ceat.201800580

Link to final VoR: https://doi.org/10.1002/ceat.201800580

This article is protected by copyright. All rights reserved. 
hand, a too high value may involve an excessive power consumption of the gas-supply system [12]. Kunii and Levenspiel [1] pointed out that, generally, a distributor pressure drop between $20-40 \%$ of the bed pressure drop would be enough to ensure homogeneous flow over the entire cross section of the chamber. The pressure drop across the distributor also has a major influence on the bubble characteristics $[15,16]$. In fact, the gas distributor performance governs the particles movement in the fluidized bed by means of the bubbles formation [17]. This result is especially important for shallow beds, where bubbles quickly pass through the solids bed and erupt immediately at the bed surface [18]. Wilkinson et al. [19] reported that the influence of the air distributor on the fluidization should be particularly considered in the scale-up of units with bed height/diameter ratios lower than 5.

Different types of distribution plates are usually employed in fluidized beds, among many others, porous, perforated and bubble cap plates [20]. The perforated plate distributors are widely used in the industry because they are cheap and easy to manufacture [1]. The pressure drop of perforated plates depends on the plate thickness and the arrangement, number and diameter of the orifices [21]. The plate thickness affects the discharge coefficient and hence the pressure drop of the distributor. The lower the thickness/hole diameter ratio, the lower the plate pressure drop. Karri and Werther [20] showed that for thickness/hole diameter ratio higher than 2, the discharge coefficient can be taken as 1 . The holes number and diameter determines the distributor open area, and the plate porosity is defined as the ratio of the open area to the overall section. Malavasi et al. [22] found that, even for plates with the same porosity, the pressure drop across distributor varies with the number and location of the holes. Regarding the orifices arrangement or pitch, when the holes of the plate are more separated, the flow that enters the bed is less uniform transversely and tends to recirculate towards the space between holes and between the peripheral holes and the bed wall. According to Malavasi et al. [22], an increase in the number of holes reduces the size of the recirculation zones resulting in a lower pressure drop.

The plenum can generate gas fluctuations in the fluidized bed $[18,23]$. For low-pressure-drop distributors and small plenums, Vakhshouri and Grace [24] observed that the bed dynamics is imposed by the plenum chamber. The pressure fluctuations in the bed track those found in small plenums.

The advances in high power computing technology have improved the use of more rigorous mathematical models in process engineering. Computational Fluid Dynamics (CFD) is the implementation of complex numerical techniques in computers to solve physical problems related to the movement of fluids and related phenomena, such as mass and heat transfer, chemical reactions, among others [25]. CFD provides a very detailed solution containing local values of all relevant variables such as pressure, velocity, shear stress, turbulence properties, and temperature $[26,27]$.

There are several works regarding CFD calculations of pressure drops across single holes and different types of distributors. Within the first studies, Gan and Riffat [28] used CFD (considering the two-equation turbulence model and incompressible flow) to predict the pressure drop in orifices of perforated plates. The circular holes were represented as square ones to reduce the computational costs. This simplification allowed to predict the pressure drop across the distributor, however this study was not related to a fluidization equipment. Ngo et al. [29] used the CFD two-fluid model to evaluate the fluidynamics of a dual fluidized bed (square cross section) with a nozzle-type distributor. These authors studied the airflow within the system (plenum, distributor and fluidization chamber) by considering: a uniform gas distributor and a detailed representation of the nozzles. The simulation results showed that both systems had similar behavior regarding the prediction of the pressure drop across the fluidized bed chamber, but significant differences were found on the solid volume fraction. The results pointed out the importance of considering the detailed description of the gas distribution system. Afrooz et al. [30] studied the influence of the perforated plate orifice 
arrangement on the fluidized bed expansion and bubble formation and movement. The simulation domain included the distribution plate and the cylindrical fluidized chamber. The inlet boundary condition was imposed at the bottom of the perforated plate (i.e., neither the gas inlet pipe nor the plenum were simulated), then the gas uniformly traversed the distribution grid. The authors concluded that a triangular orifice arrangement concentrates the bubbles at the center of the bed, while a higher volume fraction of solids was found on the walls of the chamber, as compared to a radial arrangement of orifices. As above described and probably due to the high required computational costs, there are few contributions that simulated the distributor in a detailed manner together with all the components of a fluidization unit. Commonly, as an alternative to represent the perforated plate, simplified models based on empirical correlations that represent the flow macroscopically were used [31]. To this end, the software ANSYS-Fluent provides the Porous Zone and the Porous Jump models. In Porous Zone one, a momentum source term is assigned to the distributor domain, which includes pressure-loss coefficients. In the Porous Jump approach, a thin "membrane" with a pressure drop boundary condition is imposed [32]. Depypere et al. [2] represented a woven wire distributor using the simplified models above described. Based on an analysis of the CFD results, they concluded that the use of a Porous Jump Boundary condition did not give a realistic description of the air distribution in the fluidization chamber.

By means of CFD simulations, Peirano et al. [33] for low distributor pressure drops found that, the fluidized bed behavior and the dynamics of the air supply system are coupled. Therefore, to simulate by CFD the fluidized bed behavior adequately, they concluded that it is necessary to model the entire air supply system. On the other hand, based on the findings of Peirano et al [33], Depypere et al. [2] simulated a fluidized system including the gas lateral inlet pipe to the windbox, the plenum, the air distribution grid (represented as a porous media) and the fluidization chamber. Their results showed that the lateral air inlet in the plenum chamber caused a non-homogeneous airflow towards the distributor, requiring a significant grid pressure drop to obtain a fully homogenized airflow towards the expansion chamber. Although the solids bed in the fluidization chamber was not taken into account in the CFD simulations, a qualitative analysis was used to evaluate the capacity of two different woven wire grids to allow developing a uniform flow.

In this contribution, the impact of the perforated plate representation on the fluidynamics prediction of a pilot-scale conical bed is evaluated. In order to identify the sources of uneven distribution of airflow within the fluidization unit, the system is integrally modeled by CFD, by including the gas inlet pipe, plenum, perforated plate, fluidization chamber and the air outlet pipe in the computational domain. Particularly, the air distributor (perforated plate) was modeled in detail taking into account its real geometry. Different model approaches were implemented to distinguish the best way (low computational cost and accurate prediction of the system fluidynamics) to represent perforated plates distributors. Besides, several grid designs were simulated to elucidate the impact of the holes size and location on the airflow distribution. Furthermore, results and recommendations for researchers, technologists and industrial practitioners that design, simulate and/or operate fluidization units are listed.

\section{Materials and Methods}

A photograph and a schematic diagram of the equipment are shown in Fig. 1 and 2, respectively. The fluidized chamber is constituted by a stainless-steel bottom conical vessel and a cylindrical freeboard. To regulate the air flowrate, the RPM of the centrifugal blower was modified. The air distributor is a stainless-steel perforated plate of $0.0015 \mathrm{~m}$ thick with a porosity of $12.3 \%$ (Fig. 3). The geometric properties of the equipment are summarized in Tab. 1. 


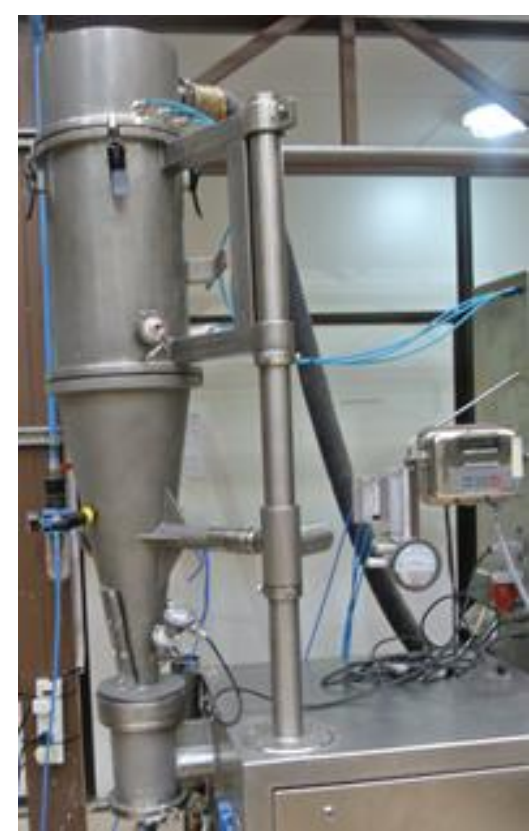

Figure 1. Photograph of the fluidization system.

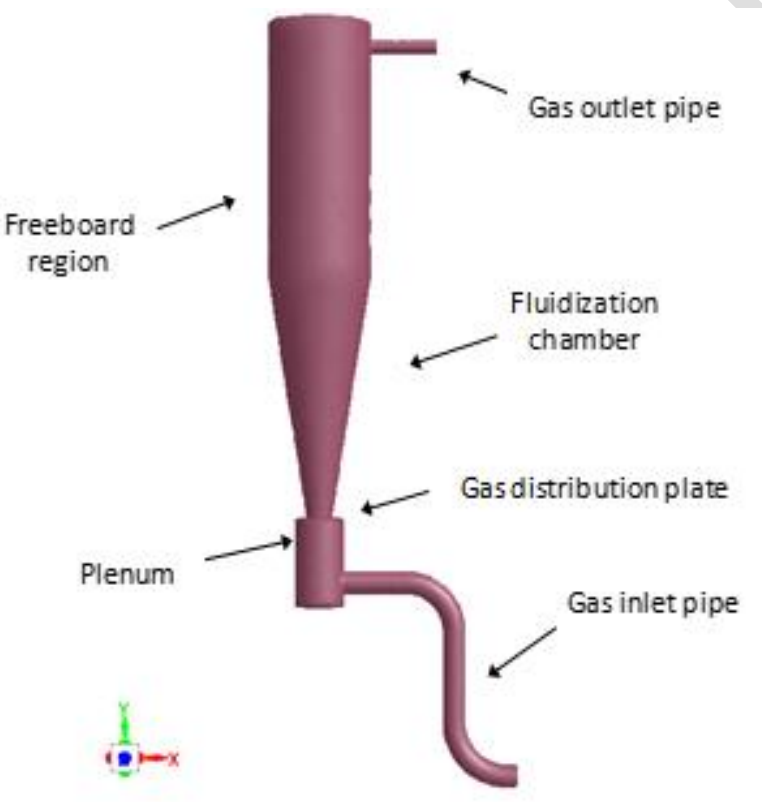

Figure 2. Schematic diagram of the fluidization system. 


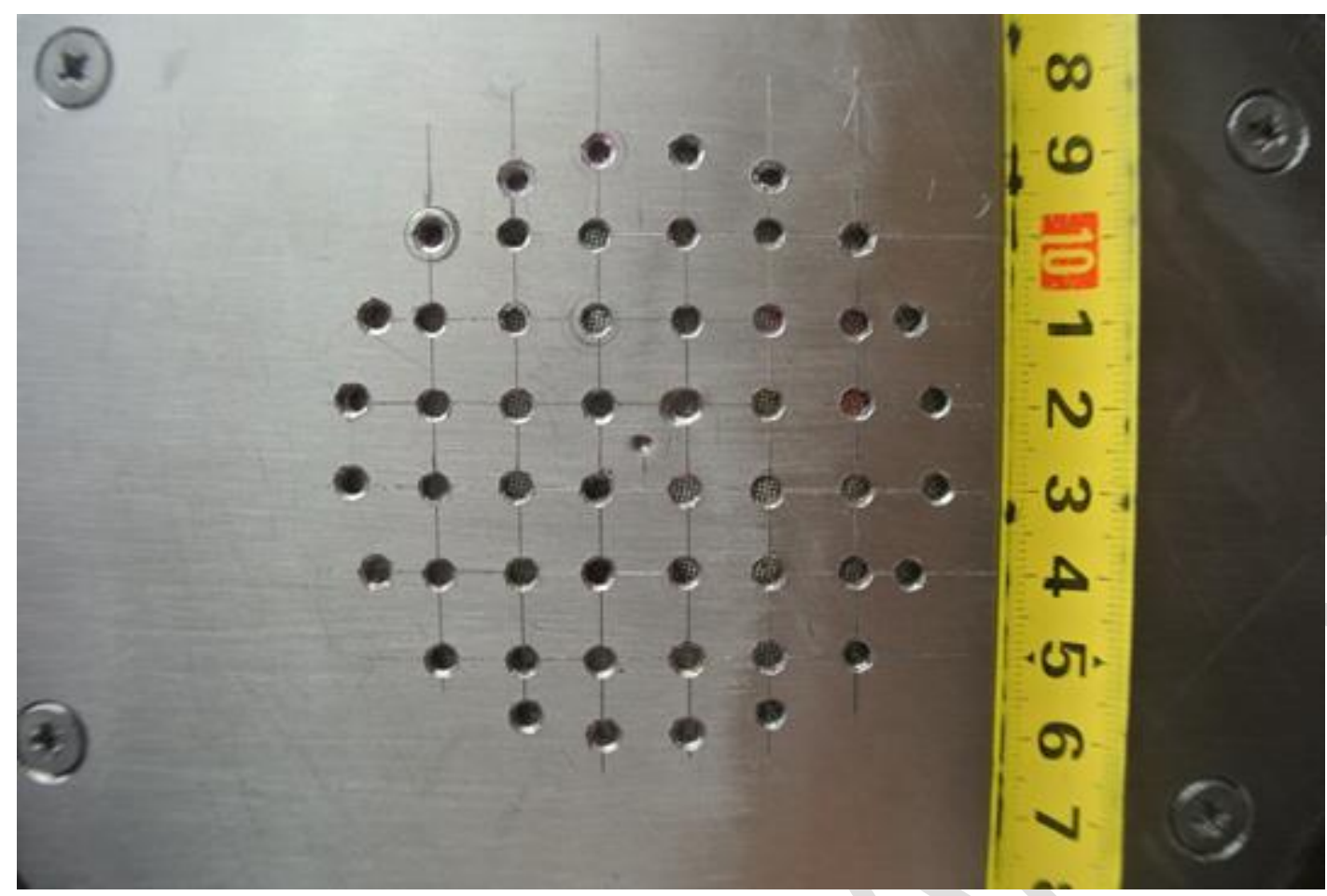

Figure 3. Detailed view of the air distributor grid.

Table 1. Dimensions of the Fluidization System.

\begin{tabular}{ll}
\hline Description & Value \\
\hline Inlet pipe diameter [m] & 0.067 \\
Inlet pipe length [m] & 0.47 \\
Plenum diameter [m] & 0.1426 \\
Plenum height [m] & 0.256 \\
$\begin{array}{l}\text { Bottom diameter of the } \\
\text { fluidization chamber [m] }\end{array}$ & 0.075 \\
$\begin{array}{l}\text { Top diameter of the fluidization } \\
\text { chamber [m] }\end{array}$ & 0.3 \\
$\begin{array}{l}\text { Height of the fluidization } \\
\text { chamber [m] }\end{array}$ & 0.70 \\
$\begin{array}{l}\text { Height of the freeboard region } \\
\text { [m] }\end{array}$ & 0.74 \\
$\begin{array}{l}\text { Outlet pipe diameter [m] } \\
\text { Outlet pipe length [m] }\end{array}$ & 0.04 \\
$\begin{array}{l}\text { Holes arrangement of the } \\
\text { perforated plate }\end{array}$ & 0.20 \\
$\begin{array}{l}\text { Orifice diameter of the } \\
\text { perforated plate [m] }\end{array}$ & Square \\
\hline
\end{tabular}


Minimum distance between

orifice centers $[\mathrm{m}]$

Perforated plate thickness [m] $\quad 0.0015$

The air flowrate was measured by an orifice flow-meter before entering the plenum. By means of a pitot tube, ten perforated plate pressure drop values were measured for air mass flowrates between $0.018 \pm 0.0006 \mathrm{~kg} \mathrm{~s}^{-1}$ to $0.033 \pm 0.001 \mathrm{~kg} \mathrm{~s}^{-1}$. Each reported pressure drop is a time average over 1minute interval. The air inlet temperature was around $18 \pm 0.3^{\circ} \mathrm{C}$ for all experiments. The uncertainty of the reported experimental values was calculated following the guidelines of Moffat [34].

To verify the air velocity patterns within the fluidization chamber, flow indicator strips were placed in different positions onto the distributor. For different air mass flowrates, the movement of the strips was observed to qualitatively identify the preferential air path.

\section{CFD modeling}

The computational fluid dynamics software ANSYS-Fluent 17.0, which uses the finite volume method, was selected for this study. Since the maximum Mach number was lower than 0.23 for the simulated scenarios, the flow can be considered as incompressible with constant physical properties. Then, the conservation of mass and momentum are given by Eqs. (1) and (2), respectively.

$\frac{\partial \rho_{g}}{\partial t}+\nabla \cdot\left(\rho_{g} \boldsymbol{u}_{\boldsymbol{g}}\right)=0$

$\frac{\partial}{\partial t}\left(\rho_{g} \boldsymbol{u}_{\boldsymbol{g}}\right)+\boldsymbol{\nabla} \cdot\left(\rho_{g} \boldsymbol{u}_{\boldsymbol{g}} \boldsymbol{u}_{\boldsymbol{g}}\right)=-\nabla P+\boldsymbol{\nabla} \cdot \overline{\overline{\boldsymbol{\tau}}}_{\boldsymbol{g}}+\rho_{g} \boldsymbol{g}$

$\rho_{g}, \boldsymbol{u}_{\boldsymbol{g}}, P, \boldsymbol{g}$ and $\overline{\overline{\boldsymbol{\tau}}}_{\boldsymbol{g}}$ are the density, velocity, pressure, gravity acceleration and stress tensor, respectively. For an incompressible fluid, the gas stress tensor can be written as [32]:

$\overline{\overline{\boldsymbol{\tau}}}_{\boldsymbol{g}}=\left(\mu_{g}+\mu_{t, g}\right)\left(\boldsymbol{\nabla} \boldsymbol{u}_{\boldsymbol{g}}-\boldsymbol{\nabla} \boldsymbol{u}_{\boldsymbol{g}}{ }^{T}\right)$

where $\mu_{g}$ and $\mu_{t, g}$ are the molecular and turbulent viscosity for the air, respectively.

To represent the turbulence effects, the realizable $k-\varepsilon$ model is chosen. For this model, the turbulent viscosity is calculated as:

$\mu_{t, g}=\rho_{g} C_{\mu} \frac{k^{2}}{\varepsilon}$

where $k$ and $\varepsilon$ are the turbulence kinetic energy and the turbulence dissipation rate, respectively. $C_{\mu}$ is a variable coefficient proposed by Reynolds [35]. $k$ and $\varepsilon$ are obtained by solving the following transport equations [36]:

$\frac{\partial}{\partial t}\left(\rho_{g} k\right)+\boldsymbol{\nabla} \cdot\left(\rho_{g} \boldsymbol{u}_{\boldsymbol{g}} k\right)=\boldsymbol{\nabla} \cdot\left[\left(\mu_{g}+\frac{\mu_{t, g}}{\sigma_{k}}\right) \boldsymbol{\nabla} k\right]+G_{k}-\rho_{g} \varepsilon$

$\frac{\partial}{\partial t}\left(\rho_{g} \varepsilon\right)+\nabla \cdot\left(\rho_{g} \boldsymbol{u}_{\boldsymbol{g}} \varepsilon\right)=\nabla \cdot\left[\left(\mu_{g}+\frac{\mu_{t, g}}{\sigma_{k}}\right) \boldsymbol{\nabla} \varepsilon\right]+\rho_{g} C_{1} S \varepsilon-1.9 \rho_{g} \frac{\varepsilon^{2}}{k+\sqrt{\varepsilon}}$

where $G_{k}$ is the turbulence kinetic energy generation due to the mean-velocity gradients, $S$ represents the modulus of the mean rate-of-strain tensor and $C_{1}$ is a variable that ensures the realizability of the $k-\varepsilon$ model $[36,37]$.

A uniform stream flow with air mass flowrate $\dot{m}_{\text {air }}$ is used as boundary condition at the inlet of the computational domain. As outlet boundary condition, atmospheric pressure is specified. At the wall, 
the no-slip boundary condition is used (i.e., the fluid velocity is zero). For the near wall treatment of the turbulence, the realizable $k-\varepsilon$ model is coupled with the Enhanced Wall Function.

The 3D geometry was generated by the ANSYS Design Modeler, and the mesh for the CFD calculations was generated using ANSYS Meshing. The generated mesh is a non-uniform one, composed by tetrahedral and prism cells. Automatic inflation was enabled with 10 layers to accurately capture the boundary layer region for any wall-bounded turbulent flow. The first cell aspect ratio option was selected to avoid high skewness on the cells near the wall.

Simulations were performed in an Intel Core i7-4790 CPU with 32Gb RAM, which provided enough computational capacity to solve the proposed model in a reasonable time. Full Multigrid (FMG) initialization method was used to estimate the steady-state model pre-solution. The steady-state results were used to initiate the transient computations [38]. The relationship between pressure and velocity corrections was estimated using the SIMPLE algorithm [2]. In addition, double precision and second order discretization schemes were used to ensure numerical accuracy. During calculations, convergence was controlled by monitoring: a) the residuals of the equations $1,2,5$ and 6 , which had to be lower than $10^{-3}$ and $b$ ) the achievement of the steady state of the pressure and velocity at different points of the computational domain.

\section{$4 \quad$ Results and Discussions}

\subsection{Validation of the perforated plate detailed model}

Before analyzing the simulation results, a mesh sensitivity study is necessary to ensure numerical accuracy. The uncertainty due to CFD discretization is estimated by following the guidelines proposed by Celik et al. [39]. In this work, the fine grid convergence index (GCI) is calculated with both the grid pressure drop and the maximum velocity of the air within holes of the grid. For the evaluation of the grid refinement error, three grids were selected with a total number of 486325, 966115 and 1785916 cells. Tab. 2 shows the results of the calculation procedure for three selected grids.

Table 2. Calculations of discretization Error.

\begin{tabular}{cll}
\hline & $\begin{array}{l}\emptyset=\text { Grid Pressure } \\
\text { drop [Pa] }\end{array}$ & $\begin{array}{l}\emptyset=\text { Maximum } \\
\text { velocity }\left[\mathrm{m} \mathrm{s}^{-1}\right]\end{array}$ \\
\hline$N_{1}, N_{2}, N_{3}$ & $\begin{array}{l}1785916,966115, \\
486325\end{array}$ & $\begin{array}{l}1785916,966115, \\
486325\end{array}$ \\
$r_{21}$ & 1.27 & 1.27 \\
$r_{32}$ & 1.31 & 1.31 \\
$\emptyset_{1}$ & 3502 & 79.95 \\
$\emptyset_{2}$ & 3562 & 80.02 \\
$\emptyset_{3}$ & 4342 & 101 \\
$p$ & 9.51 & 21.3 \\
$\emptyset_{\text {ext }}^{21}$ & 3495 & 79.95 \\
$e_{a}^{21}[\%]$ & $1.7 \%$ & $0.09 \%$ \\
$e_{\text {ext }}^{21}[\%]$ & $0.19 \%$ & $0.0006 \%$ \\
$G C I_{\text {fine }}^{21}$ & $0.25 \%$ & $0.0007 \%$ \\
\hline
\end{tabular}

This article is protected by copyright. All rights reserved. 
[\%]

The approximate relative error $\left(e_{a}\right)$ and grid convergence index $(G C I)$ are respectively about $1.7 \%$ and $0.25 \%$ for the pressure analysis, and about $0.09 \%$ and $0.0007 \%$ for the velocity analysis. As the pressure and velocity obtained for the two finer grids are so close, the errors obtained are acceptable and further grid refinement would significantly increase processing time with only negligible increase in accuracy. Therefore, 0.97 million cells were used for the remainder of the study. For this mesh, the average skewness is 0.286 (standard deviation of 0.144 ), value that indicates a good mesh quality [40]. Regarding the air fluidynamics near the walls, the average $y^{+}$value was always about 1 indicating that the Enhanced Wall Function was appropriate to model the laminar sub-layer [41]. The mesh is greatly refined close to the plate orifices. The air distributor model based on a detailed representation of the orifices is named Model 1.

The experimental and CFD predictions of the pressure drop across the air distributor are compared in Fig. 4. The grid pressure drop true values are believed, with $95 \%$ confidence, to lie within $\pm 1.4 \%$ of the reported values. The error bars related to the pressure drop measurements are negligible compared to the error bars corresponding to the air flowrate measurements. Because of this, the pressure drop error bars are not shown in Fig. 4. For the studied range of air mass flowrates, Model 1 pressure drops are in good agreement with experimental data, indicating that the detailed representation of the plate orifices allows to predict the pressure drop across the grid accurately.

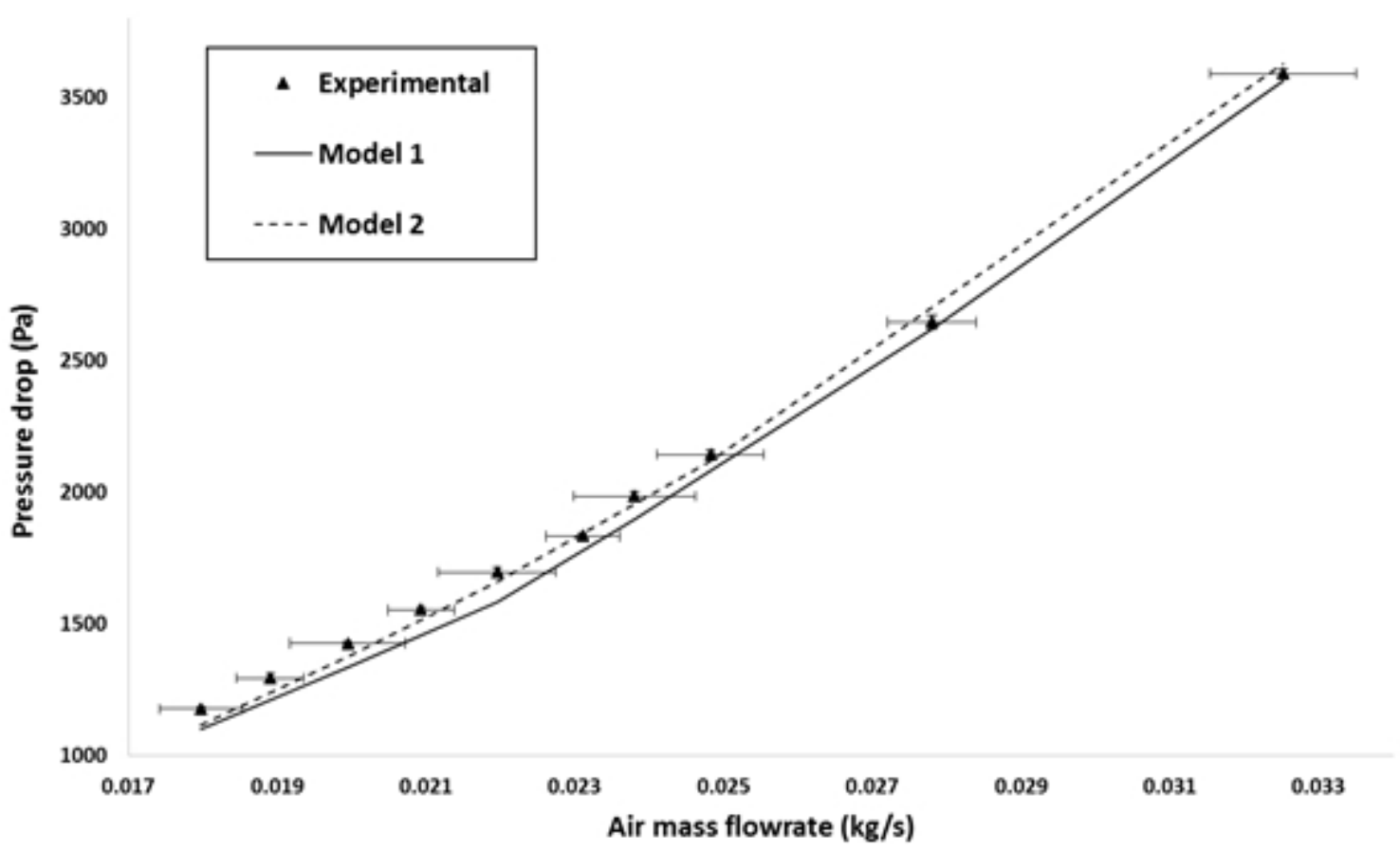

Figure 4. Experimental pressure drops across the air distributor and CFD-predicted values using Models 1 and 2.

\subsection{Analysis of the airflow}

For an air mass flowrate of $0.022 \pm 0.0008 \mathrm{~kg} \mathrm{~s}^{-1}$ (mean superficial velocity above the grid of $4 \mathrm{~m} / \mathrm{s}$ ), Fig. 5 .a shows the air pathlines within the equipment. The colors describe different air velocity ranges. The maximum velocity for the color map was set at $10 \mathrm{~m} \mathrm{~s}^{-1}$, to better appreciate the flow 
changes. According to Fig. 5.a, the airflow inside the plenum was not uniform. The higher air velocities, besides those found at the windbox inlet, were observed on the left side of the plenum. On its right side a recirculation zone was detected. The air pattern behavior was due to the combined effect of the air entrance from the right side and a relatively small plenum height, as was previously reported by Depypere et al. [2]. These authors, by using the Porous Zone model to represent the distribution grid, found similar velocity profiles in the plenum. Although the airflow pattern that reaches the distributor was non-uniform, the air pathlines emerging from the plate are almost parallel to the vertical axis and only slightly inclined to the right. Therefore, the distributor substantially improves the flow homogeneity. Fig. 5.b shows the air flow lines in the fluidized system when the mass air flowrate is increased to $0.033 \pm 0.001 \mathrm{~kg} \mathrm{~s}^{-1}$ (mean superficial velocity above the grid of $6 \mathrm{~m} \mathrm{~s}^{-1}$ ). The maximum velocity for the color map was set at $15 \mathrm{~m} \mathrm{~s}^{-1}$, to keep the same relationship between this variable and the superficial velocity above the grid than for the case of Fig. 5.a. For the highest flowrate, the flow was not uniform in the conical region of the fluidization chamber. Moreover, a slow swirl appeared near the left wall of the fluidizing chamber.
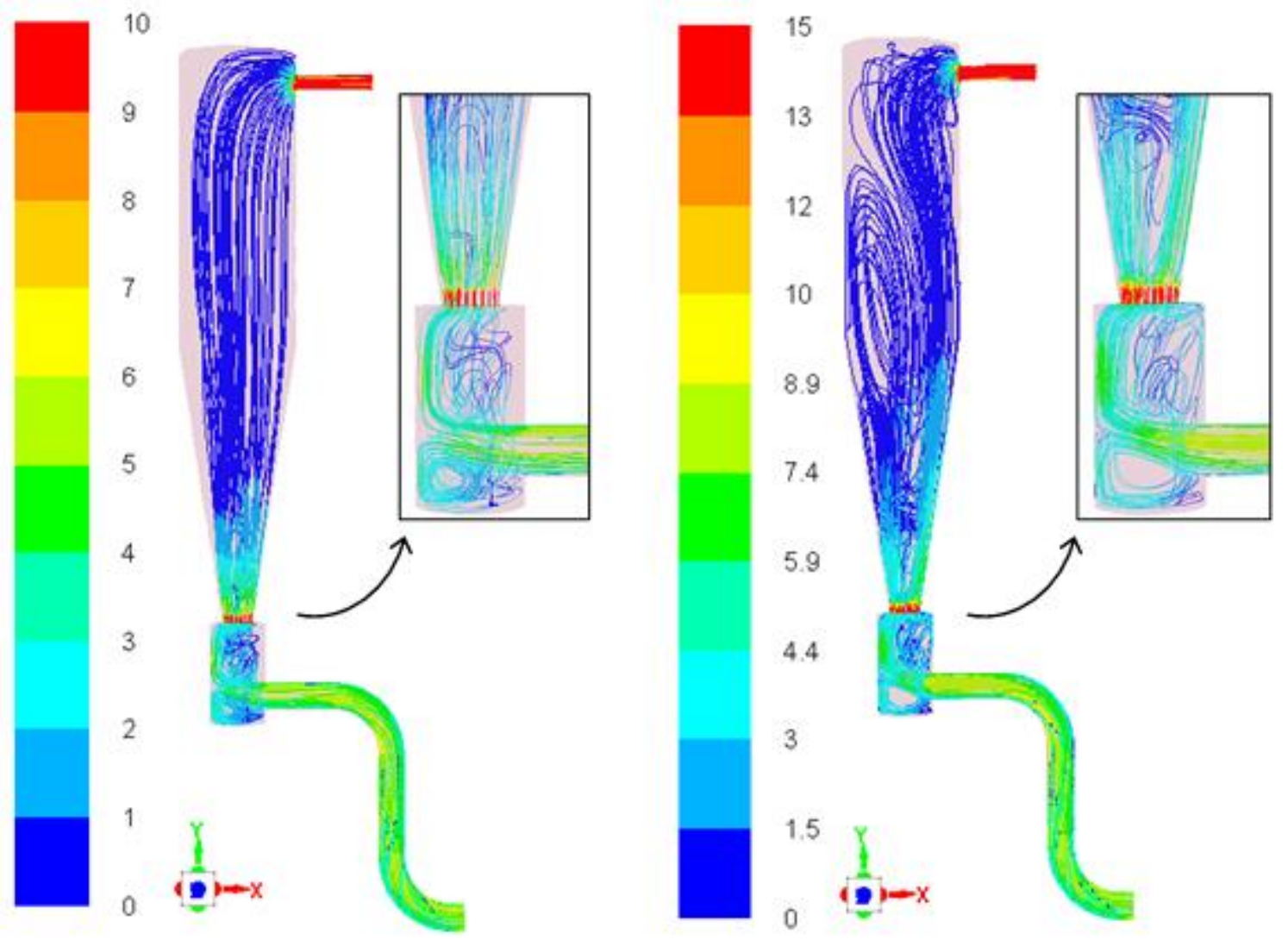

Figure 5. Air pathlines for air mass flowrates of: a) 0.022 and b) $0.033 \mathrm{~kg} \mathrm{~s}^{-1}$. The colors map corresponds to the velocity magnitude $\left(\mathrm{m} \mathrm{s}^{-1}\right)$.

To further analyze the fluidynamics within the unit, the CFD-predicted contours of the air velocity magnitude are given in Fig. 6 . For an air mass flowrate of $0.022 \pm 0.0008 \mathrm{~kg} / \mathrm{s}$, Fig. 6 .a reveals that the air velocity near the chamber walls was higher than in the center. This behavior is attributed to a lower redistribution of the axial momentum of the flow on the space between peripheral orifices and chamber wall compared to the one produced between the central holes. Moreover, at a height of about 1 distributor diameter, the air velocity in the walls became about 3 times the velocity observed in the central core. Fig. 6.a also shows that the air velocity has an asymmetric behavior. In fact, higher velocities on the right half of the fluidization chamber were found. This effect is much more 
pronounced when the air mass flowrate was increased to $0.033 \pm 0.001 \mathrm{~kg} \mathrm{~s}^{-1}$, as shown in Fig. 6.b. The velocity differences at a height of about 1 distributor diameter are more noticeable. This result was qualitatively verified in the experimental unit by means of a simple experiment. As was abovementioned, flow indicator strips were placed in different positions onto the distributor. For all the air mass flowrates, it was found that the free end of the strips lifted and shifted towards the walls of the right side of the chamber. These qualitative results are in good agreement with the CFD predictions. The observed flow asymmetry is attributed to two main causes: a) the flow maintained part of its tangential velocity as it passed through the distributor and b) the lateral location of the outlet pipe disturbed the downstream airflow.
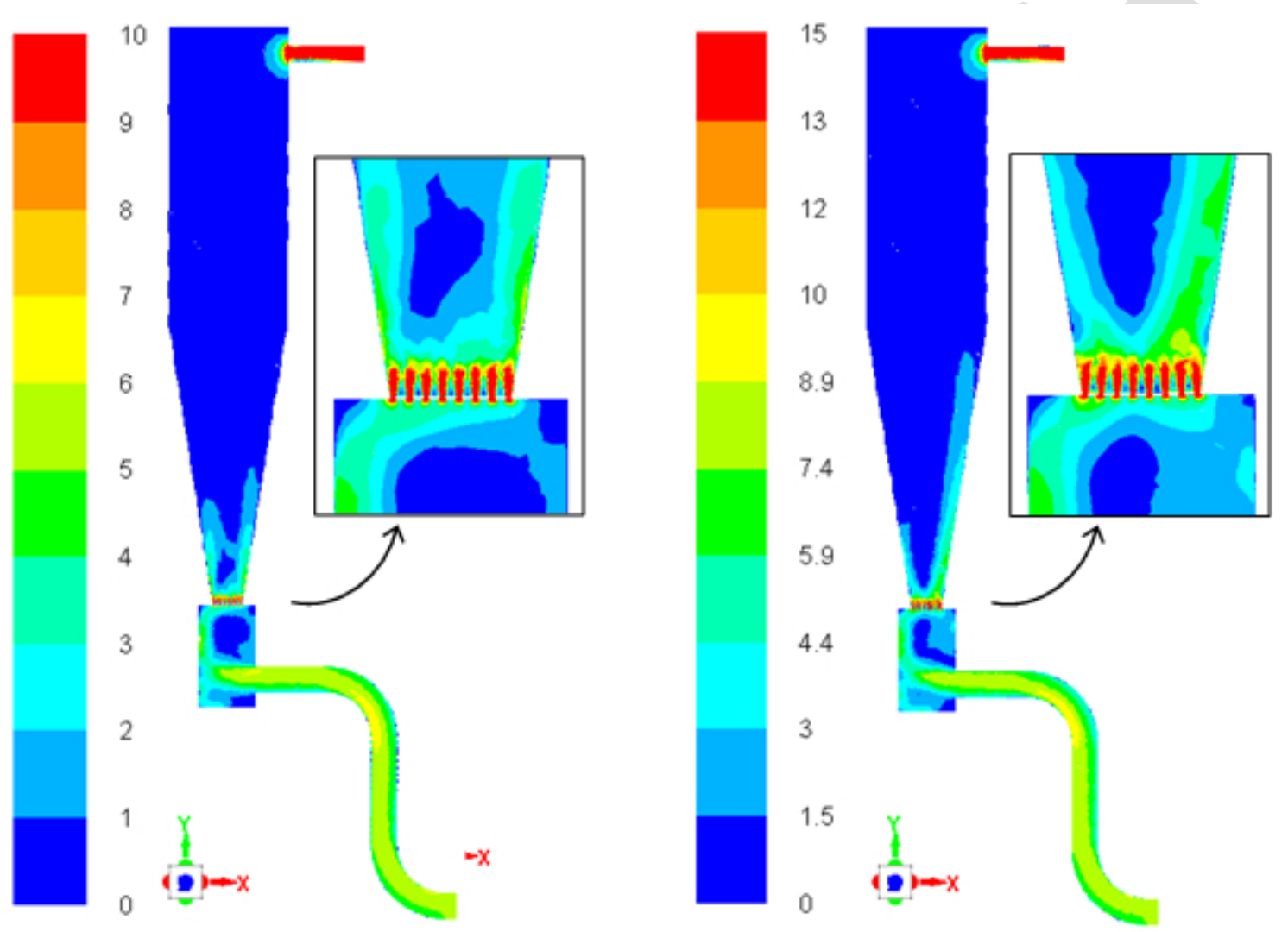

Figure 6. Air velocity contour plot for air mass flowrates in the XY plane ( $z=0.005 \mathrm{~m})$ of: a) 0.022 and b) $0.033 \mathrm{~kg} \mathrm{~s}^{-1}$. The colors map corresponds to the velocity magnitude $\left(\mathrm{m} \mathrm{s}^{-1}\right)$.

In order to analyze the influence of the plenum on the air velocity patterns above the distributor, the computational domain was modified by suppressing the inlet lateral pipe. Instead, the inlet boundary condition was imposed directly on the bottom surface of the plenum. For the air mass flowrate of $0.033 \pm 0.001 \mathrm{~kg} \mathrm{~s}^{-1}$, Fig. 7.a shows the air pathlines for this new representation of the system. Within the plenum, as expected, the airflow is uniform and the pathlines were parallel to the axial axis. According to Fig. 7.a, the flow did not appear to be disturbed by the air outlet pipe in the conical chamber. Fig. 7.b shows a contour map for the velocity magnitude, for the same conditions that those of Fig. 7.a. At different $z$ positions, the contour maps indicated flow asymmetry, even though the air flow pattern reaching the distributor was completely homogeneous. Therefore, the flow asymmetry found for the real unit geometry cannot be only attributed to the plenum design. 

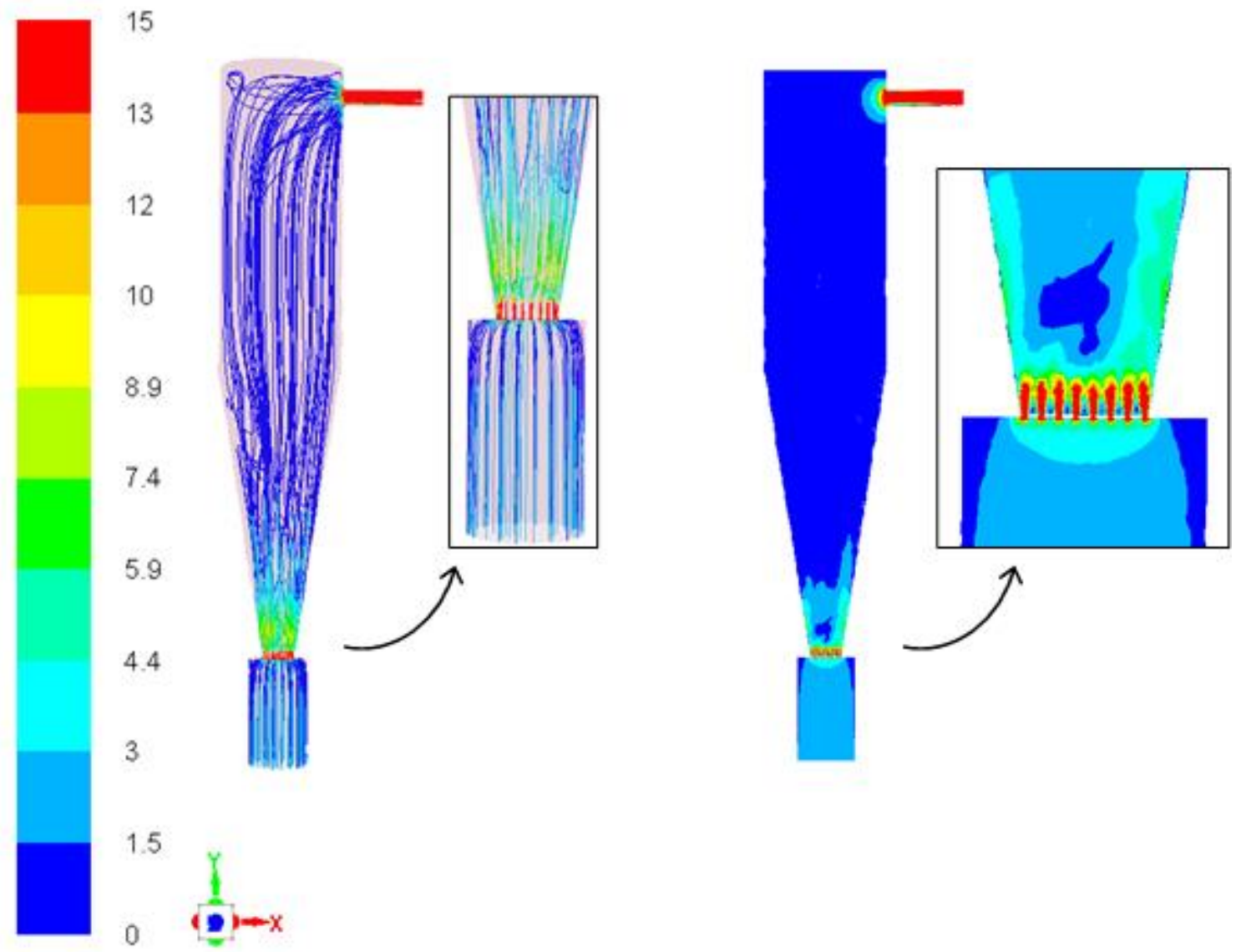

Figure 7. Pathlines and contour map of the air velocity magnitude $(\mathrm{m} / \mathrm{s})$ in the $X Y$ plane $(z=0.005 \mathrm{~m})$ for an inlet mass flowrate of $0.033 \mathrm{~kg} / \mathrm{s}$, resulting by imposing directly an homogeneous flow at the bottom surface of the plenum.

To investigate whether the position of the lateral pipe relative to the inlet pipe location has any effect on the flow non-uniformity in the fluidization chamber, the computational domain (which maintained the real plenum design), was modified by locating the outlet pipe on the left hand side (data not shown). The simulations demonstrated that the velocities were still high on the right half of the fluidization chamber and a low-velocity swirl appeared near the left wall. In fact, an airflow behavior similar to that showed in Fig. 5.b was found. Therefore, the location of the air outlet pipe did not affect the air flow qualitatively.

The effect of the outlet-pipe diameter on the flow in the fluidization chamber was also studied. To this end, the system was modified by increasing the outlet pipe diameter by $100 \%$ (from 4 to $8 \mathrm{~cm}$ ). For an air mass flowrate of $0.033 \pm 0.001 \mathrm{~kg} \mathrm{~s}^{-1}$, the airflow behavior below the distributor for the bigger diameter was similar (Fig. 8.a) to that found for the smaller one (Fig. 5.b). However, Fig. 8.a indicates that the pathlines within the chamber were more straight compared to the other one estimated for the smaller outlet pipe diameter (Fig. 5.b). According to the contour map of the air velocity magnitude presented in Fig. 8.b, still higher velocities were observed near the walls, preferentially towards the right side. 

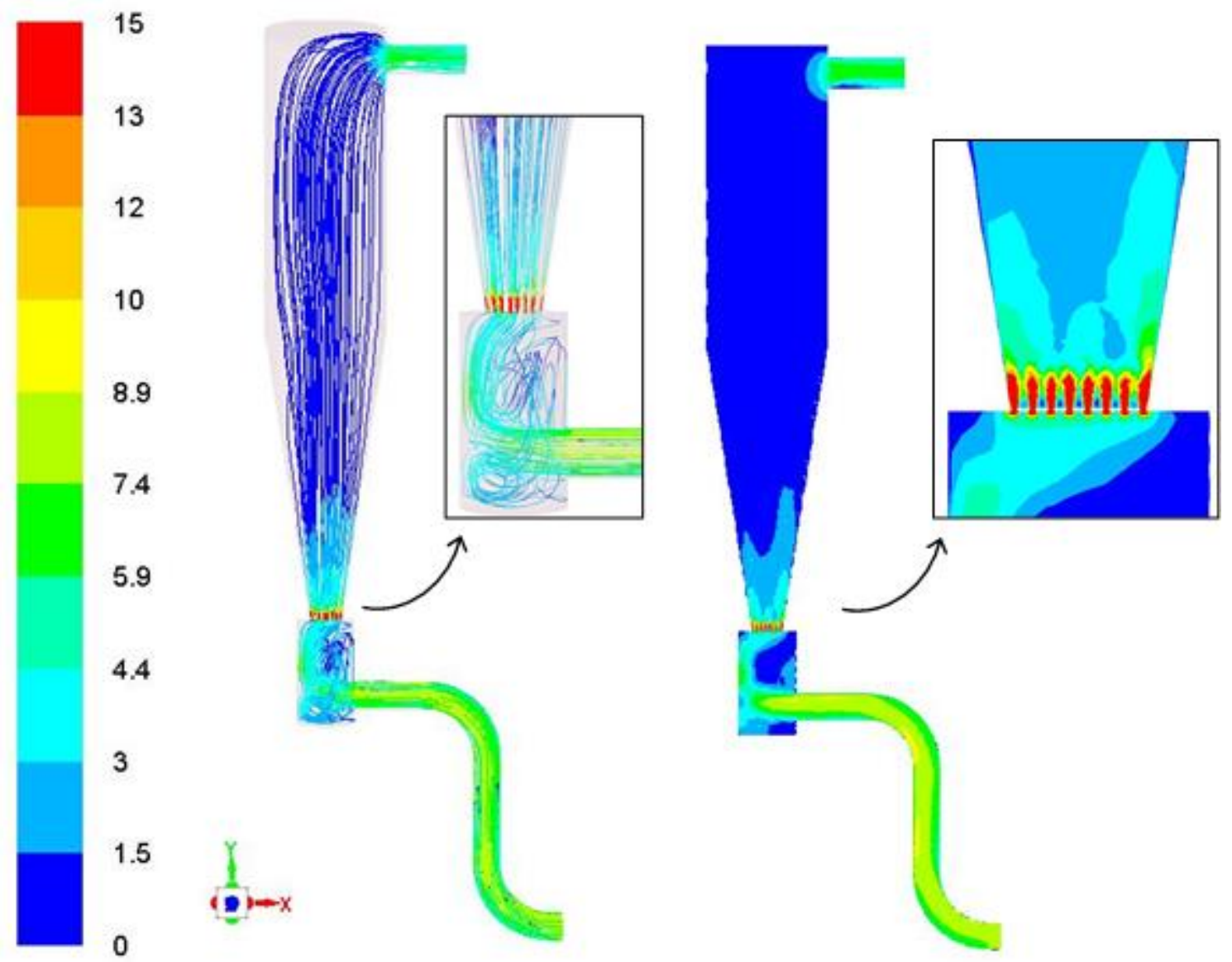

Figure 8. Pathlines and contour map of the air velocity magnitude $(\mathrm{m} / \mathrm{s})$ in the $X Y$ plane $(z=0.005 \mathrm{~m})$ for an inlet mass flowrate of $0.033 \mathrm{~kg} \mathrm{~s}^{-1}$ (outlet pipe diameter $=0.08 \mathrm{~m}$ ).

\subsection{Influence of the holes location in the perforated plate on the airflow}

As mentioned previously, the distributor holes located at the periphery of the plate are very close to the wall. This arrangement was attributed to cause higher air velocities near the walls with respect to those found in the central core. To prove this hypothesis, three additional simulations maintaining the grid porosity were performed. Firstly, the pitch was reduced (6\%), causing a distance increase between the peripheral holes and the walls. For the air mass flowrate of $0.033 \pm 0.001 \mathrm{~kg} \mathrm{~s}^{-1}$, Fig. 9 shows a velocity magnitude contour map around the distributor for three different distributor design. When the peripheral holes were separated $4.7 \mathrm{~mm}$ from walls, the air from all the holes is evenly distributed in all directions when entering the chamber. Although the velocity in the center of the chamber was slightly higher than the values found near the walls, a better homogeneity of the air flow was observed with respect to the one predicted for the real perforated plate (Fig. 6.b). For a second additional simulation the pitch was further decreased (15\%). For this case, with the peripheral holes separated $7.8 \mathrm{~mm}$ walls, Fig. 9 shows that the flow was not uniform, the air jets overlapped each other producing a faster central core. Finally, the peripheral holes of the real distributor were suppressed. For this case, the base case pitch was maintained constant, while the diameter of the inner holes was increased to maintain the plate porosity. The new diameter of the holes was $4.3 \mathrm{~mm}$. For the third case, Fig. 9 shows a similar behavior of airflow than the one showed in the case of pitch decreased (15\%), however bigger zones of high velocities were found in the fluidization chamber. Although the porosity of the perforated plate was kept constant, the holes distribution and size impacted on the air velocity profile. 

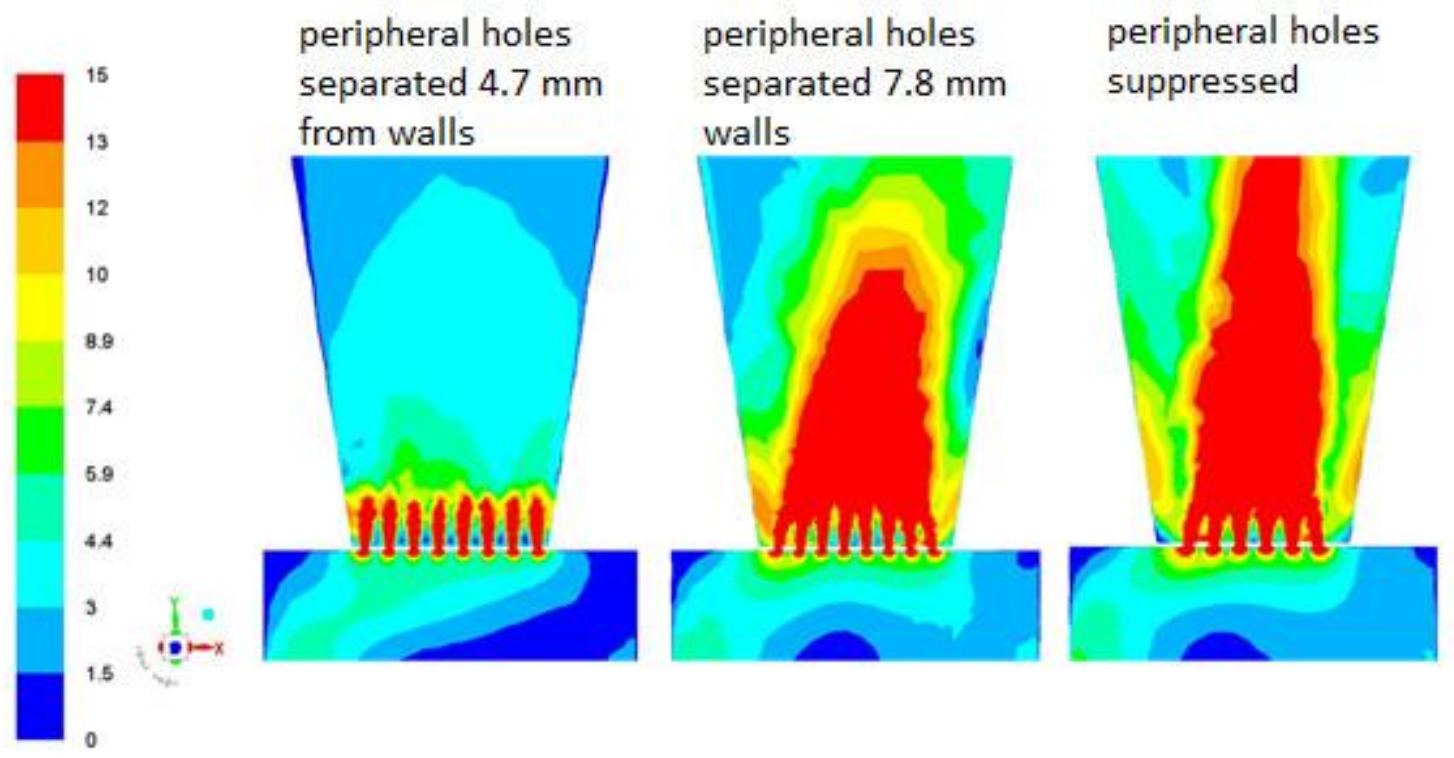

Figure 9. Contour map of the air velocity magnitude for three grid designs $\left(\mathrm{m} \mathrm{s}^{-1}\right)$ in the XY plane $(z=0.005 \mathrm{~m})$ for an inlet mass flowrate of $0.033 \mathrm{~kg} \mathrm{~s}^{-1}$.

\subsection{Simplified perforated plate representation: porous media modeling}

As mentioned above, 0.97 million mesh cells were required to accurately simulate the complete fluidization unit. Approximately $50 \%$ of these cells were found in the perforated plate and its surroundings. When the movement of the particles within the bed needs to be simulated, the detailed description of the perforated plate may lead to prohibitive computational costs [42]. For this reason, a lower computational cost model was implemented by representing the air distributor domain as a porous media. Specifically, the Porous Zone model (Model 2) was selected [40]. For this model, the following source term was included in the momentum equations in the axial direction:

$\Delta P_{P Z}=\frac{\mu_{g}}{\alpha} h v_{i}+C_{2} \frac{1}{2} \rho_{g} h v_{i}^{2}$

where $v_{i}$ is the superficial air velocity in the principal direction within the Porous Zone, $\alpha$ is the porous media permeability, $h$ the plate thickness and $C_{2}$ is a parameter that relates the pressure drop in the porous media with the velocity that crosses the porous zone due to turbulent effects. $\alpha$ and $C_{2}$ are required as inlet data in the porous media simulation.

In order to generate a fully predictive model, the parameters $\alpha$ and $C_{2}$ were not obtained from experimental pressure drop values. Instead, an isolated hole (diameter $0.0034 \mathrm{~m}$ ) was simulated by a 2D planar representation to obtain the orifice pressure drop. The air mass flowrate per orifice was used as inlet boundary condition for the 2D hole model, while atmospheric pressure was the outlet boundary condition. According to Guo et al. [31], the Shear Stress Transport (SST) k- $\omega$ turbulence model is better than k-epsilon model in resolving the flow separation and generally provides a better performance. The Shear Stress Transport (SST) $k-\omega$ turbulence model has also proven to be good for cases with adverse pressure gradients [43]. For this reason, the single hole simulations were performed by using the Shear Stress Transport (SST) k- $\omega$ turbulence model. Similar to Model 1, the procedure of by Celik et al. [39] to estimate the uncertainty due to CFD discretization was applied (data not shown), obtaining a validated mesh of about 218000 elements.

Based on the 2D simulations, the predicted pressure drop and velocity values were used to fit the parameters of equation (7). ( $\alpha=5.4 \times 10^{-9} \mathrm{~m}^{2} ; \mathrm{C}_{2}=81851 \mathrm{~m}^{-1}$ for the axial direction). The Fluent implementation of the porous media also requires the $C_{2}$ coefficient value for the non-principal 
directions. For the simulated grid, these components were set to zero because diffusion along nonprincipal axes does not occur in the studied perforated plate. The porosity of the porous media was the perforated plate open area. The validated computational domain of Model 2 had about 580000 elements (the discretization uncertainty was evaluated by means of the Celik et al. [39] procedure), for this reason the simulations require less computing time than the detailed grid model. Fig. 4 shows that the calculated pressure drops by means of Model 2 adequately represent the experimental data and the predicted values by Model 1 . Therefore, it is verified that the Porous Zone model provides a good representation of the pressure drop across the air distributor.

For an air mass flowrate of $0.033 \pm 0.001 \mathrm{~kg} \mathrm{~s}^{-1}$, Fig. 10.a shows the air pathlines across the distributor represented by Model 2 and within the fluidization chamber. The results showed that the air moved preferentially through the center of the fluidization chamber. This behavior did not agree neither with the results obtained by the detailed simulation of the air distributor (see Fig. 5.b) nor the qualitatively experiment that used flow indicator strips. The prediction differences were also observed in the contour plots of the air velocity magnitude (compare Fig. 6.b with Fig. 10.b). Due to the idealized representation of the porous media model, air jets emerging from the grid were not predicted. Even though the pressure drop across the distributor was well predicted by Model 2, the chamber airflow was not well represented, being then the Model 1 a better option to describe the air fluidynamics above the distributor. However, both models predicted similar flow patterns within the plenum. Therefore, the distributor grid model did not affect the upstream air pathlines.
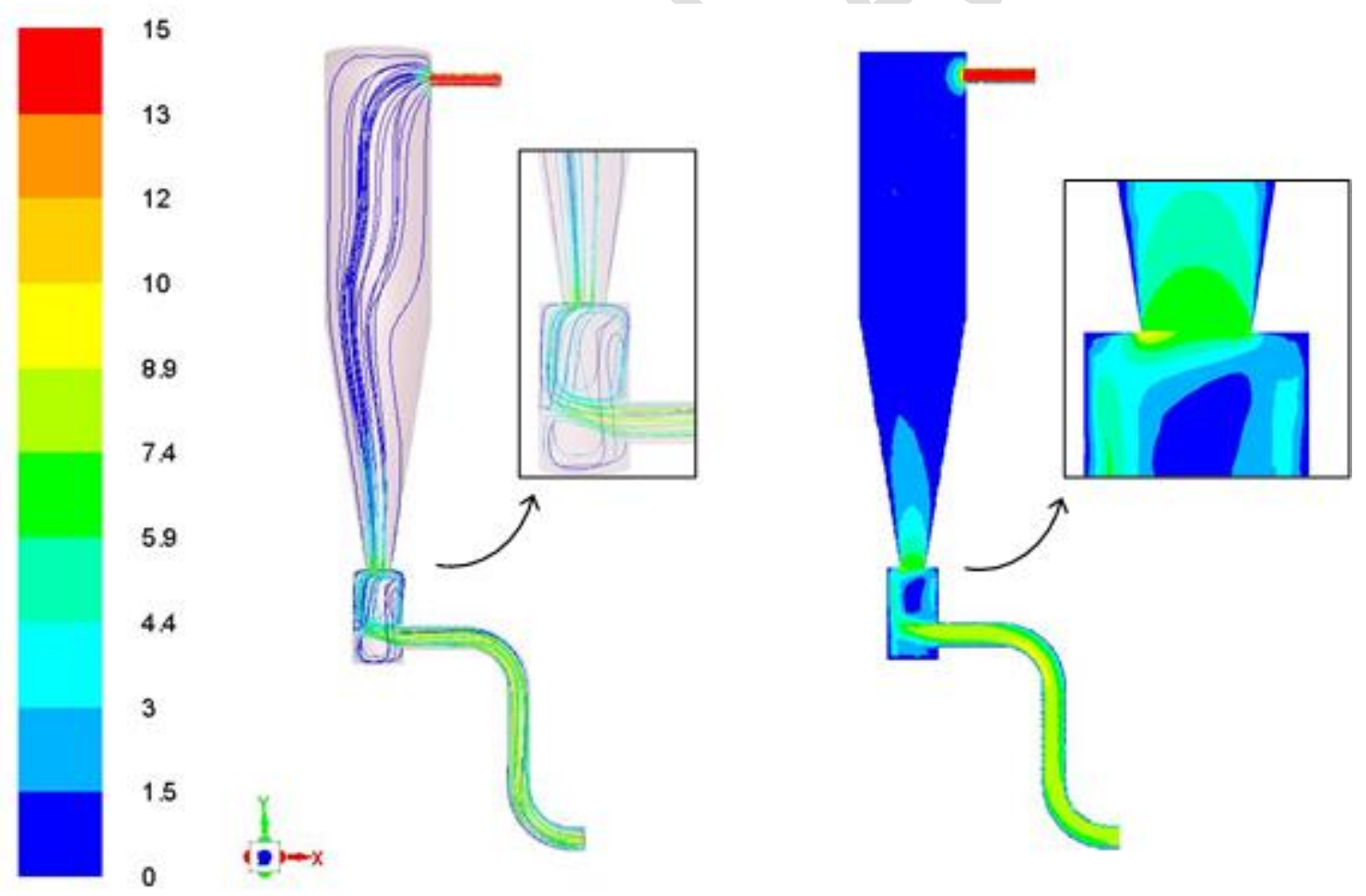

Figure 10. Pathlines and contour map of the air velocity magnitude $\left(\mathrm{m} \mathrm{s}^{-1}\right)$ in the XY plane $(z=0.005 \mathrm{~m})$. for an inlet mass flowrate of $0.033 \mathrm{~kg} \mathrm{~s}^{-1}$, by using Model 2 .

Sathiyamoorthy and Horio [16], for coarse and dense materials fluidized at operating velocities much above the minimum fluidization one, demonstrated that the distributor pressure drop during fluidization is similar to its empty bed value. Then, for these cases, Model 1 can be used to provide the air velocity profiles to be used as an inlet boundary condition for the bed. If the distributor pressure drop can change from the value corresponding to the empty bed and the computational

This article is protected by copyright. All rights reserved. 
costs can be afforded, multiphase simulations considering the detailed representation of the grid are necessary $[29,30]$. Otherwise, the detailed grid CFD model should be used to develop simplified distributor geometries or models (e.g. porous media with a spatially porosity distribution) capable to emulate equivalent downstream pressure and velocity profiles as suggested by Larsson et al [44].

\section{Conclusions}

This paper presents the development of a CFD model to represent the airflow within a conical fluidization unit. The computational domain including the gas inlet pipe, plenum, perforated plate (represented by detailed and simplified models), fluidization chamber and the air outlet pipe was considered to integrally study the system. Although both the plenum, the perforated plate and the outlet pipe greatly affect the distribution of the flow inside the fluidization chamber, the plenum design was the main responsible of the observed flow asymmetry within the fluidization chamber. Moreover, the original air distributor grid was unable to fully homogenize the outlet airflow. For the simulated fluidization system, the diameter of the gas outlet pipe affected the flow distribution inside the fluidization chamber more than its radial location, particularly when high air flow-rates are used. Therefore, the freeboard above a fluidization chamber is necessary not only to allow the particles to disengage before the gas leaves the equipment but also to favor that the outlet pipe does not disturb the upstream air pathlines if the outlet pipe diameter is small.

Regarding the perforated plate design, the grid porosity and the diameter and location of the orifices greatly impacted the airflow within the fluidization chamber. Particularly, the distance of the peripheral orifices to the fluidization chamber wall was found as a critical design parameter. Short distances caused higher air velocities close to the wall, while large distances promoted a preferentially central flow. This behavior can be attributed to the presence of swirls when the distance of the peripheral orifices increases. The orifice diameter is the key parameter to mitigate the downstream flow asymmetry. In fact, for constant porosity, the bigger the orifice holes the higher the propagation of the flow asymmetry caused by the plenum. The porous media simulations for the distribution grid allowed to predict pressure drops accurately, however did not provide good results to represent the airflow within the fluidization chamber. This simplified model should not be used for systems where downstream flow asymmetry is expected. In those cases, the detailed grid model should be coupled with the multiphase representation of the fluidized bed. 0.97 and 0.58 million mesh cells were required to accurately simulate the fluidization unit by means of the detailed and simplified model, respectively. This represent a $40 \%$ reduction of the mesh elements if the simplified model is used. For this reason, if the computational costs are prohibitive, a detailed grid model should be used to provide qualitative and quantitative information to build grid simplified models capable to represent the airflow after the distributor accurately.

Although the performed study allowed understanding of the sensitivity of the airflow patterns with the design of the main parts that form the fluidized system, the addition of the particulate phase is necessary to link all the fluidization variables together definitely. This pending improvement deserves further research.

\section{Acknowledgment}

The authors thank Dra. Fernanda Cabrera and Dra. Agustina Di Batista (PLAPIQUI; UNS-CONICET) for their technical assistance. 


\section{Funding}

Authors express their gratitude for the financial support by the Consejo de Investigaciones Científicas y Técnicas (CONICET), the Agencia Nacional de Promoción Científica y Tecnológica (ANPCYT), and the Universidad Nacional del Sur (UNS). 


\section{Symbols used}

\section{Nomenclature}

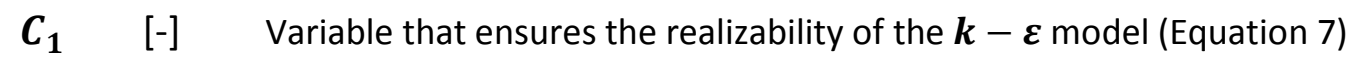

$\boldsymbol{C}_{\boldsymbol{\mu}} \quad[-] \quad$ Variable in Equation 4 that relates the mean flow and the turbulence

$\boldsymbol{e}_{\boldsymbol{a}}^{\boldsymbol{l k}} \quad[-] \quad$ Approximate relative error

$\boldsymbol{e}_{\boldsymbol{e x t}}^{\boldsymbol{l k}} \quad[-] \quad$ Extrapolated relative error

g [ $\left[\mathrm{m} \mathrm{s}^{-2}\right]$ Gravity acceleration,

$\boldsymbol{G C I}_{\text {fine }}^{\boldsymbol{l k}} \quad[-] \quad$ Fine-grid convergence index

$\boldsymbol{G}_{\boldsymbol{k}} \quad\left[\mathrm{kg} \mathrm{m}^{-1} \mathrm{~s}^{3}\right] \quad$ Generation of turbulence kinetic energy due to the mean velocity gradients,

h [m] Perforated plate thickness

$\boldsymbol{k} \quad\left[\mathrm{m}^{2} \mathrm{~s}^{-2}\right]$ Turbulent kinetic energy

$\boldsymbol{N} \quad[\#] \quad$ Total number of cell (\#)

$\boldsymbol{p} \quad[-] \quad$ Apparent order

$\boldsymbol{P}[\mathrm{Pa}]$ Pressure

$\boldsymbol{r}_{l \boldsymbol{k}} \quad[-] \quad$ Grid refinement factor

$S \quad\left[\mathrm{~s}^{-1}\right] \quad$ Modulus of the mean rate-of-strain tensor

t [s] Time

$\boldsymbol{u}_{\boldsymbol{g}}\left[\mathrm{m} \mathrm{s}^{-1}\right]$ Vectorial gas velocity

\section{Greek letters}

$\boldsymbol{\alpha} \quad\left[\mathrm{m}^{2}\right]$ Permeability

$\Delta \mathbf{P}_{\mathbf{P Z}}[\mathrm{Pa}]$ Momentum source term in Porous Zone

$\boldsymbol{\varepsilon} \quad\left[\mathrm{m}^{2} \mathrm{~s}^{-3}\right]$ Turbulent Kinetic Energy Dissipation

$\boldsymbol{\mu}_{\mathrm{g}} \quad$ [Pa s] Molecular viscosity

$\boldsymbol{\mu}_{\mathrm{t}, \mathrm{g}} \quad[\mathrm{Pa} \mathrm{s}]$ Turbulent viscosity

$\boldsymbol{\rho}_{\mathrm{g}}\left[\mathrm{kg} \mathrm{m}^{-3}\right]$ Gas density

$\overline{\overline{\mathbf{\tau}}}_{\mathbf{g}} \quad[\mathrm{Pa}] \quad$ Stress Tensor

$\emptyset_{\mathbf{k}} \quad[-] \quad$ Solution on the $\mathrm{k}^{\text {th }}$ grid of variable $\varnothing$

$\emptyset_{\mathbf{e x t}}^{\mathbf{l k}} \quad[-] \quad$ Extrapolated solution on the $\mathrm{I}^{\text {th }}$ grid of variable $\varnothing$

\section{Sub- and Superscripts}

T Transpose 


\section{References}

[1] D. Kunii, O. Levenspiel, Fluidization Engineering, 2nd ed., Butterworth-Heinemann, Stoneham 1991.

[2] F. Depypere, J. G. Pieters, K. Dewettinck, Powder Technol., 2004, 145(3), 176-189. DOI: 10.1016/j.powtec.2004.06.005

[3] J. P. K. Seville, U. Tuzun, R. Clift, Processing of Particulate Solids, 1st ed., Blackie Academic \& Professional, Chapman\& Hall, London 1997.

[4] F. Bonniol, C. Sierra, R. Occelli, L. Tadrist, Powder Technol., 2009, 189(1), 14-24. DOI: 10.1016/j.powtec.2008.05.011

[5] A. Brems, C. W. Chan, J. P. K. Seville, D. Parker, J. Baeyens, Adv. Powder Technol., 2011, 22(2), 155-161.DOI: 10.1016/j.apt.2010.07.012

[6] C. Chan, J. P. K. Seville, J. Baeyens, The 13th International Conference on Fluidization - New Paradigm in Fluidization Engineering, (Eds: S. D. Kim, Y. Kang, J. K. Lee, Y. C. Seo), ECI Digital Archives, Gyeong-ju 2010, 1-8.

[7] A. T. Pemberton, J. F. Davidson, Chem. Eng. Sci., 1986, 41(2), 253-262. DOI: 10.1016/00092509(86)87006-3

[8] A. Venkata Narayana, B. Sumalatha, K. Kiran Kumar, A. Ranganath Reddy, T. C. Venkateswarulu, J. Chem. Pharm. Res., 2015, 7(5), 578-588.

[9] W. Senadeera, B. R. Bhandari, G. Young, B., Wijesinghe, Dry. Technol., 2000, 18(7), 15371557. DOI: $10.1080 / 07373930008917792$

[10] M., Wormsbecker, T. S., Pugsley, H., Tanfara, The 12th International Conference on Fluidization - New Horizons in Fluidization Engineering, (Eds: F. Berruti, X. Bi, T. Pugsley), University of Saskatchewan, Vancouver, 2007, 815-822.

[11] A. Shukrie, S. Anuar, A. N. Oumer, Engineering, Technology \& Applied Science Research, 2016, 6(3), 1029-1034.

[12] Z. Luo, Y. Zhao, Q. Chen, X. Tao, M. Fan, Int. J. Miner. Process., 2004, 74(1-4), 337-341. DOI: 10.1016/j.minpro.2004.04.002

[13] C. Sobrino, N. Ellis, M. de Vega, Powder Technol., 2009, 189(1), 25-33. DOI:

10.1016/j.powtec.2008.05.012

[14] D. Geldart, J. Baeyens, Powder Technol., 1985, 42(1), 67-78. DOI: 10.1016/00325910(85)80039-5

[15] A. Svensson, F. Johnsson, B. Leckner, Powder Technol., 1996, 86(3), 299-312. DOI: 10.1016/0032-5910(95)03055-7

[16] D. Sathiyamoorthy, M. Horio, Chem. Eng. J., 2003, 93(2), 151-161. DOI: 10.1016/S13858947(02)00257-7

[17] R. Lau, W. S. B. Sim, R. Mo, Can. J. Chem. Eng., 2009, 87(6), 847-854. DOI: 10.1002/cjce.20224

[18] H. Kage, M. Agari, H. Ogura, Y. Matsuno, Adv. Powder Technol., 2000, 11(4), 459-475. DOI: 10.1163/156855200750172060

[19] P. M. Wilkinson, A. P. Spek, L. L. van Dierendonck, AlChE J., 1992, 38(4), 544-554. DOI: 10.1002/aic.690380408 
[20] S. B. R. Karry, J. Werther, in Handbook of Fluidization and Fluid-Particle Systems, (Ed: W.C. Yang), CRC Press. Boca Raton 2003.

[21] L. Mörl, S. Heinrich, M. Peglow, Granulation, 1st Ed., Elsevier Series in Handbook of Powder Technology, Vol. 11, 21-188. Elsevier, Amsterdam 2007.

[22] S. Malavasi, G. Messa, U., Fratino, A. Pagano, Flow Meas. Instrum., 2012, 28, 57-66. DOI: 10.1016/j.flowmeasinst.2012.07.006

[23] C. S. Chyang, K. Lieu, S. S. Hong, J. Chinese Inst. Chem. Eng., 2008, 39(6), 685-692. DOI: 10.1016/j.jcice.2008.05.011

[24] K. Vakhshouri, J. R. Grace, Particuology, 2010, 8(1), 2-12. DOI: 10.1016/j.partic.2009.05.005

[25] S. Benyahia, M. Syamlal, T. J. O’Brien, Powder Technol., 2005, 156(2-3), 62-72. DOI: 10.1016/j.powtec.2005.04.002

[26] G. C. Cheng, R. P. Koomullil, B. K. Soni, Appl. Numer. Math., 2005, 55(3), 264-282. DOI: 10.1016/j.apnum.2005.04.030

[27] M. Deza, F. Battaglia, ASME J. Fluids Eng., 2013, 135(10), 101301 (1-11). DOI: $10.1115 / 1.4024750$

[28] G. Gan, S. B. Riffat, Exp. Therm. Fluid Sci., 1997, 14(2), 160-165. DOI: 10.1016/S08941777(96)00041-6

[29] S. I. Ngo, Y. I. Lim, B. H. Song, U. D. Lee, J. W. Lee, J. H. Song, Powder Technol., 2015, 275, 188-198. DOI: 10.1016/j.powtec.2015.02.017

[30] I. E. Afrooz, C. M. Sinnathambi, S. Karuppanan, D. L. C. Ching, ARPN J. Eng. Appl. Sci., 2016, 11(20), 11954-11959.

[31] B. Y. Guo, Q. F. Hou, A. B. Yu, L. F. Li, J. Guo, Chem. Eng. Res. Des., 2013, 91(3), 403-408. DOI: 10.1016/j.cherd.2012.10.004

[32] ANSYS Inc., ANSYS Fluent Theory Guide, Release 18.1, ANSYS Inc., 2017.

[33] E. Peirano, V. Delloume, F. Johnsson, B. Leckner, O. Simonin, Powder Technol., 2002, 122(1), 69-82. DOI: 10.1016/S0032-5910(01)00393-X

[34] R. J. Moffat, Exp. Therm. Fluid Sci., 1988, 1(1), 3-17. DOI: 10.1016/0894-1777(88)90043-X

[35] W. C. Reynolds, AGARD Lect. Ser., 1987, 86(1).

[36] T. H. Shih, W. W. Liou, A. Shabbir, Z. Yang, J. Zhu, Comput. Fluids, 1995, 24(August), 227-238. DOI: 10.1016/0045-7930(94)00032-T

[37] P. Bradshaw, B. E. Launder, J. L. Lumley, ASME J. Fluids Eng., 1996, 118(2), 243-247. DOI: $10.1115 / 1.2817369$

[38] M. W. Woo, L. X. Huang, A. S. Mujumdar, W. R. W. Daud, in Spray Drying Technology, (Eds: M. W. Woo, A. S. Mujumdar, W. R. W. Daud) Singapore, 2010, 1-36

[39] I. B. Celik, U. Ghia, P. J. Roache, C. J. Freitas, H. Coleman, P. E. Raad, ASME J. Fluids Eng., 2008, 130(078001), 1-4. DOI: 10.1115/1.2960953

[40] ANSYS Inc., ANSYS Fluent User's Guide, Release 18.1, ANSYS Inc., 2017.

[41] N. El Gharbi, R. Absi, A. Benzaoui, E. H. Amara, in International Conference on Computational Methods for Energy Engineering and Environment: ICCM3E, Sousse, 2009, 185-189. 
[42] N. Andrianov, F. Coquel, M. Postel, Q. H. Tran, in Computational Methods in Multiphase Flow III, (Eds: A. A. Mammoli, C. A. Brebbia), WIT Press, Lisbon 2005, 295-304.

[43] F. R. Menter, AIAA J., 1994, 32(8), 1598-1605. DOI: 10.2514/3.12149

[44] H. Larsson, P. A. Schjøtt Andersen, E. Byström, K. V. Gernaey, U. Krühne, Ind. Eng. Chem. Res., 2017, 56(14), 3853-3865. DOI: 10.1021/acs.iecr.7b00224

This article is protected by copyright. All rights reserved. 


\section{Entry for the Table of Contents}

Research Article: Experiments and CFD simulations were carried out in a pilot-scale conical bed to study the impact of the gas inlet pipe, plenum, perforated plate, fluidization chamber and the air outlet pipe on the fluidynamics behavior. Regarding the perforated plate design, the distance of the peripheral orifices to the fluidization chamber wall was found as a critical design parameter.
Design impact on airflow patterns in fluidization units

C. Renaudo*, D. Bertin, V. Bucalá Chem. Eng. Technol. 20XX, $X X(X)$, xxxx...xxxx

This article is protected by copyright. All rights reserved. 